\title{
Biomechanical testing of rectangular humeral shaft prosthesis: higher torsional stability without increased fracture risk
}

\author{
Matthias P. Flury • Werner Schmoelz • \\ Ulrich Schreiber $\cdot$ Joerg Goldhahn
}

Received: 28 December 2009 / Published online: 21 September 2010

(C) The Author(s) 2010. This article is published with open access at Springerlink.com

\begin{abstract}
Background Rectangular cementless femur shaft prostheses have a higher primary stability than round shafts. A novel rectangular humeral shaft design was tested with two questions: does the rectangular design cause a higher fracture risk during implantation than round designs, and does it increase the torsional stiffness?

Materials and methods Two series with six paired human humeri (total 24) were tested on one side with the rectangular shaft and on the contralateral side with a round shaft. In the first series, the shaft implantation was carried out with a constant speed of $100 \mathrm{~mm} / \mathrm{min}$ and the maximum force was measured when the fracture occurred. In the second series, the implants were preloaded with $50 \mathrm{~N}$ and then rotated at $2^{\circ}$ per second with monitoring of the torsional torque.

Results The maximum force at fracture showed no significant difference for the two designs $(p=0.34)$. Higher age and low bone density reduced the force required for
\end{abstract}

\author{
M. P. Flury ( $\square)$ \\ Orthopaedic Surgery, Schulthess Clinic, \\ Lengghalde 2, 8008 Zurich, Switzerland \\ e-mail: matthias.flury@kws.ch \\ W. Schmoelz \\ Trauma Surgery, Medical University Innsbruck, \\ Innsbruck, Austria

\section{U. Schreiber} \\ Biomechanics, Technical University of Munich, \\ Munich, Germany \\ J. Goldhahn \\ Research Upper Extremity, Schulthess Clinic, \\ Zurich, Switzerland
}

fracture. The rectangular shaft showed significant higher torsional moments $(p<0.05)$.

Conclusions In biomechanical testing, the rectangular shaft had a significantly higher primary torsional stability than the round shaft without a higher risk of fracture during cementless implantation. Fracture risk and torsional stability are influenced by age and bone density.

Keywords Shoulder prosthesis - Humerus - Uncemented · Stability $\cdot$ Fracture $\cdot$ Torsional stiffness

\section{Introduction}

The introduction of third-generation prostheses with the possibility of anatomically reconstructing the centre of rotation of the shoulder joint has been a breakthrough in shoulder joint replacement [2]. Since then, further developments have resulted in a greater number of uncemented prosthetic humeral stems with various designs.

Cementless implantation is widely used in hip joint replacements [6]. In the femur, the prosthesis design has an important role in primary stability. It has been shown that stems with diaphyseal edges or fins have greater primary stability than round stems, particularly with respect to rotational stability [9, 13]. In addition, diaphyseal fixation with a good press fit has advantages over metaphyseal fixation [5]. However, there are no comparable data on the humerus, although high rates of radiolucent lines have been published for a couple of uncemented humeral components of round cross-sectional stem design [7, 10, 12].

The superior biomechanical properties already identified for diaphyseal fixation with a rectangular stem provided the rationale for developing a similar design for the humerus as well. The main objective was to achieve good primary 
stability of the implant, especially with respect to rotational stability (cf. Fig. 1).

Stability is extremely important, as third- and fourthgeneration modular prostheses reconstruct the natural offset of the centre of rotation in relation to the shaft axis, and this creates a torsional moment on the stem.

However, the proximal humerus has certain anatomical differences compared to the femur. The cortical bone is usually much thinner than in the proximal femur, especially when the skeleton is osteoporotic. To achieve a good initial press fit necessary for cementless fixation, it has to be assumed that there will be a greater danger of humerus fracture. This risk has been confirmed in literature, where intraoperative fractures have been described with an incidence of up to 3\% [8]. It was not previously known whether the risk was further potentiated by a rectangular cross-sectional design with force peaks along the edges. If the humerus does fracture during the operation, further surgical management has to be decided intraoperatively depending on the fracture type [3].

In view of these considerations, we carried out the present study to address the following questions: (1) Is there an increased risk of fracture with a rectangular stem compared to an uncemented round stem; in other words, which design has the greater potential to fracture the humerus during implantation? (2) What type of fracture occurs (longitudinal fissure or multiple fragment fracture)? (3) Does the stem with rectangular cross-sectional design provide greater primary rotational stability than the round one?

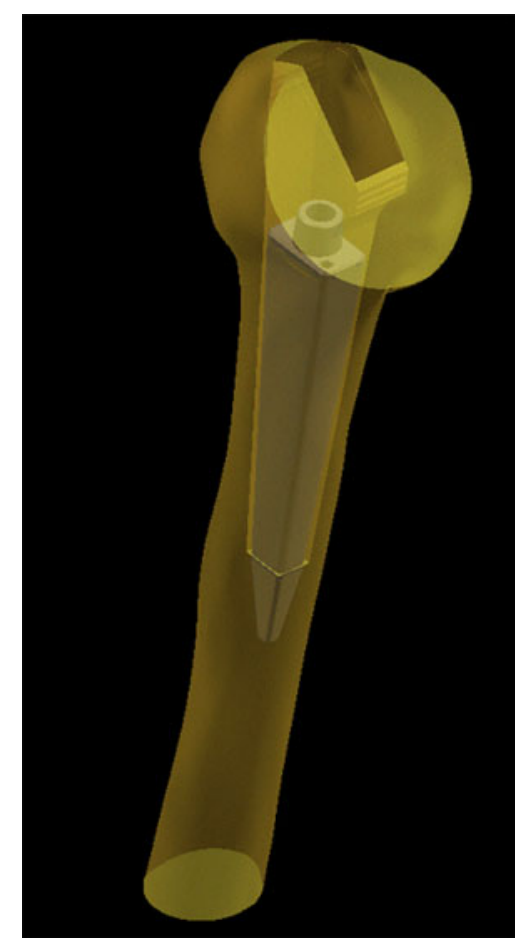

Fig. 1 Rectangular stem implanted in the humeral diaphysis

\section{Materials and methods}

Prostheses and implantation technique

The Promos ${ }^{\circledR}$ (Smith\&Nephew Orthopaedics Inc, Rotkreuz, Switzerland) shoulder joint prosthesis with an uncemented rectangular cross-sectional stem [11] was tested against the Univers ${ }^{\circledR}$ (Arthrex Inc, Naples FL, USA) prosthesis with an uncemented round stem [4]. (cf. Fig. 2).

The two prostheses require a similar surgical technique for implantation. After resecting the head of the humerus, the medullary canal is first opened with a round awl. Starting with the smallest broach, the medullary canal is successively enlarged by gently seating each broach until it reaches the upper mark or it has cortical contact. As soon as a tight press fit is achieved, the broach is replaced by the definitive shaft of corresponding size.

\section{Preliminary study}

The potential for the prosthesis stems to fracture the humeral shaft during implantation was tested in a preliminary study using artificial humeri (Sawbones ${ }^{\circledR}$, Sweden), with the help of drop hammer testing equipment. However, no standardised or reproducible shaft fractures could be obtained even when varying the drop height and weight. Furthermore, the wall thickness of the artificial bones was

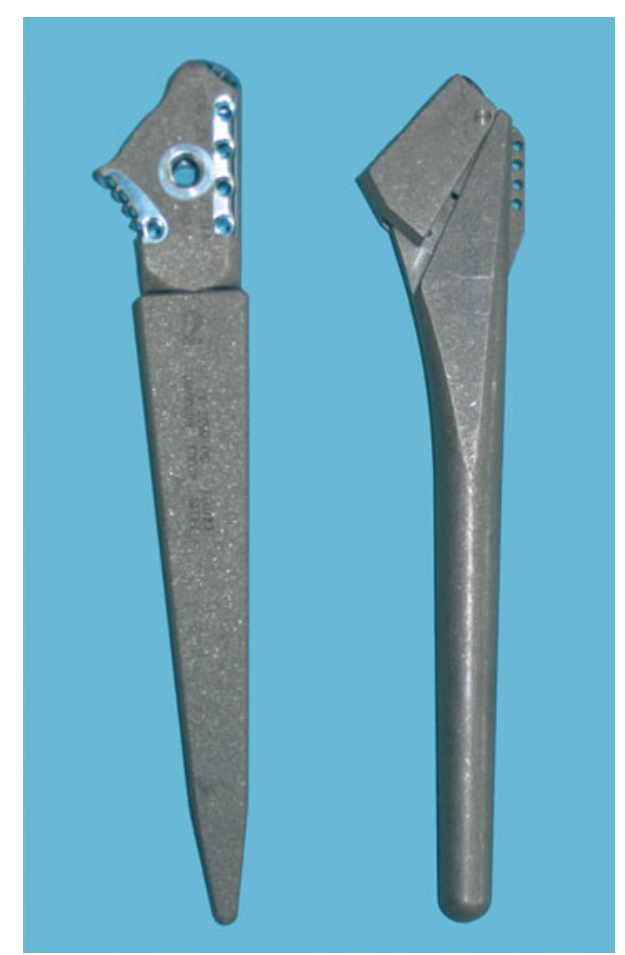

Fig. 2 On the left rectangular stem (Promos ${ }^{\circledR}$, Smith \& Nephew Inc., Aarau, Switzerland), and on the right round stem (Univers ${ }^{\circledR}$, Arthrex Inc, Naples FL, USA) 
Table 1 Details of specimens used for test 1: shaft fracture

\begin{tabular}{|c|c|c|c|c|c|c|c|c|c|c|}
\hline $\begin{array}{l}\text { Humeri } \\
\text { pair }\end{array}$ & No & Age & Sex & Side & $\begin{array}{l}\text { Size } \\
(\mathrm{cm})\end{array}$ & Weight (kg) & Shaft type & $\begin{array}{l}\text { Shaft } \\
\text { size }\end{array}$ & $\begin{array}{l}\text { Force to } \\
\text { burst }[\mathrm{N}]\end{array}$ & $\begin{array}{l}\text { Sum of forces of } \\
\text { all rasp insertions }[\mathrm{N}]\end{array}$ \\
\hline \multirow[t]{2}{*}{1} & P01 & 88 & $\mathrm{~F}$ & Left & 158 & 59 & Round & 11 & $1,630.5$ & $2,855.5$ \\
\hline & $\mathrm{P} 02$ & & & Right & & & Rectangular & 1 & $3,224.9$ & $9,692.6$ \\
\hline \multirow[t]{2}{*}{2} & P03 & 44 & M & Left & 177 & 92 & Round & 10 & $6,625.6$ & $18,201.1$ \\
\hline & P04 & & & Right & & & Rectangular & 2 & $7,340.5$ & $17,502.3$ \\
\hline \multirow[t]{2}{*}{3} & P05 & 63 & $\mathrm{~F}$ & Left & 159 & 52 & Round & 7 & $2,740.9$ & $12,615.8$ \\
\hline & P06 & & & Right & & & Rectangular & $\__{01}$ & $1,860.6$ & $1,860.6$ \\
\hline \multirow[t]{2}{*}{4} & P07 & 84 & $\mathrm{~F}$ & Left & 149 & 61 & Round & 8 & $1,083.6$ & $2,358.7$ \\
\hline & P08 & & & Right & & & Rectangular & _01 & $1,081.2$ & $1,089.3$ \\
\hline \multirow[t]{2}{*}{5} & P09 & 83 & M & Left & 175 & 73 & Round & 12 & 417.5 & $2,663.3$ \\
\hline & P10 & & & Right & & & Rectangular & 3 & $3,068.7$ & $4,726.3$ \\
\hline \multirow[t]{6}{*}{6} & P11 & 46 & M & Left & 176 & 68 & Round & 10 & $3,721.1$ & $17,601.9$ \\
\hline & P12 & & & Right & & & Rectangular & 1 & $2,884.8$ & $8,445.5$ \\
\hline & & & & & Mean & & Round & & $2,703.2$ & $9,382.7$ \\
\hline & & & & & $\mathrm{SD}$ & & & & $\pm 2,058.4$ & $\pm 6,986.5$ \\
\hline & & & & & Mean & & Rectangular & & $3,243.5$ & $7,219.2$ \\
\hline & & & & & $\mathrm{SD}$ & & & & $\pm 1,980.4$ & $\pm 5,565.8$ \\
\hline
\end{tabular}

very inconsistent. The potential to cause fractures was therefore tested on human humeri with the aid of a materials testing machine.

\section{Specimens}

The two implant systems were tested on paired human humeri. Six matched pairs of bones were treated separately for each question. Details of the specimens used for each test series, giving age and gender, are shown in Tables 1 and 2. Specimens used to determine the maximum force to burst had a median age of 73 years (range 44-88 years). The torsion experiments were carried out on bones with a median age of 58.5 years (range 4470 years). Specimens were fresh frozen at $-28^{\circ} \mathrm{C}$, allowed to thaw out overnight at $6^{\circ} \mathrm{C}$ and then prepared at room temperature. All the soft tissues were removed and the bones shortened to an overall length of $25 \mathrm{~cm}$. The distal ends were embedded in polymethylmethacrylate (PMMA) (Technovit 3040, Heraeus Kulzer, Werheim, Germany) with the longitudinal axis fixed perpendicular to the base plate.

Before testing, standardised X-rays of the specimens were taken and CT scans carried out: there were no abnormal findings. An experienced orthopaedic surgeon determined the appropriate size of implant from the preoperative $\mathrm{X}$-rays in ap-view, in accordance with the manufacturers' guidelines using the correct templates. Bone mineral density (BMD) in the humeral head of the specimens used for measuring torsional stiffness was determined from the qCT scans.
Test setup

Two series of tests with a quasi-static arrangement were run in this study; both series were carried out using a biaxial servohydraulic machine for materials testing (858 Minibionix II, MTS, MN, USA). In order to minimise any possible shear forces, the base plate of the specimen was fixed to an $x-y$ table on ball bearings, allowing free movement in the $x-y$ plane.

The potential of the stem to fracture the humeral shaft was measured by reaming the canal at a constant axial rate of $100 \mathrm{~mm} / \mathrm{min}$. Each broach was introduced as far as the upper limit indicated by the manufacturer, then changed to the next bigger size, until a fracture occurred: as shown by a sudden drop in the force measured.

In the second series, the prosthesis was implanted with a tight press fit to the bone and then preloaded with $50 \mathrm{~N}$ for mechanical stabilisation. The torsional stiffness of the prosthesis bone construct was assessed by applying torsional displacement at two degrees per second. Measurements were made up to an implant rotation of $30^{\circ}$.

Outcome measure: humeral shaft fracture (burst)

The maximum force required to fracture the bone (force to burst in N) was measured, and the sum of the applied forces of the individual broaches determined. The pattern of the fracture was also recorded. In addition, the implant size at which fracture occurred was noted and compared with the planned size established preoperatively from the X-rays. Table 1 gives an overview of the all the specimens. 
Table 2 Details of specimens used for test 2: torsional stability

\begin{tabular}{lllllllrc}
\hline $\begin{array}{l}\text { Humeri } \\
\text { pair }\end{array}$ & No & Age & Sex & Side & $\begin{array}{l}\text { BMD in } \\
\mathrm{mg} / \mathrm{cm}^{3}\end{array}$ & Shaft type & $\begin{array}{l}\text { Shaft } \\
\text { size }\end{array}$ & $\begin{array}{l}\text { Maximum } \\
\text { torque [Nm] }\end{array}$ \\
\hline 1 & P01 & 68 & M & Left & 147.6 & Round & 11 & 2.99 \\
& P02 & & & Right & 162.7 & Rectangular & 3 & 15.70 \\
2 & P03 & 66 & M & Right & 166.8 & Round & 11 & 23.40 \\
& P04 & & & Left & 160.4 & Rectangular & 2 & 19.96 \\
3 & P05 & 70 & M & Right & 112.1 & Round & 11 & 4.70 \\
& P06 & & & Left & 112.6 & Rectangular & 4 & 9.91 \\
4 & P07 & 51 & F & Right & 152.2 & Round & 8 & 8.33 \\
& P08 & & & Left & 144.4 & Rectangular & 1 & 18.50 \\
5 & P09 & 49 & M & Left & 94.1 & Round & 11 & 5.33 \\
& P10 & & & Right & 130.5 & Rectangular & 1.5 & 12.21 \\
6 & P11 & 44 & M & Left & 144.9 & Round & 7 & 8.15 \\
& P12 & & & Right & 141.8 & Rectangular & 1 & 17.05 \\
& & & Mean & & Round & & 8.82 \\
& & & & SD & & & & \pm 7.43 \\
& & & Mean & & Rectangular & & 15.55 \\
& & & & & & & \pm 3.83 \\
& & & & & & &
\end{tabular}

Outcome measure: torsional stability

The torsional moment in $\mathrm{Nm}$ was recorded continuously and the maximum torque during rotation to $30^{\circ}$ was determined. The angular displacement and type of the construct failure were evaluated. An overview of the specimens used can be found in Table 2 .

Statistical analysis was carried out using SPSS $^{\circledR}$ for Windows version 15.0 (SPSS Inc, Chicago, IL, USA). A paired $t$ test was used to compare the two prosthesis stems in both test series and establish any differences between the two implants. The relation to the age of the specimen was tested using Pearson's correlation. A value of $p<0.05$ was considered to be statistically significant.

\section{Results}

Humeral shaft fracture (burst)

There was no significant difference between the two prostheses in either the maximum force that led to the fracture of the humeral shaft $(p=0.39)$ or in the sum of the maximum forces applied to the individual broaches $(p=0.46)$. Table 1 shows the individual data.

There was a significant correlation between the maximum force required to fracture the humerus and the age of the specimen $(r=9.722, p<0.05)$; less force was required with increasing age of the bone. Comparing the two prosthesis designs (Fig. 3), it can be seen that the force to burst was considerably more affected by the age of the specimen

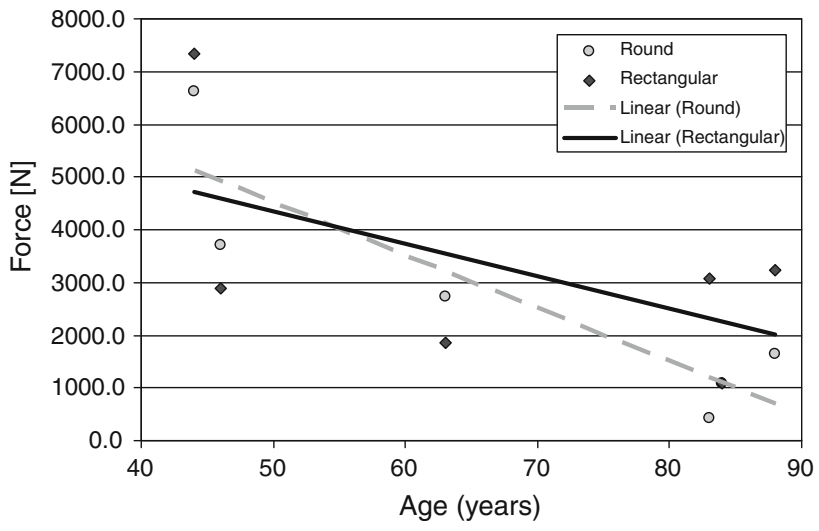

Fig. 3 Correlation between maximum force required for fracture [N] and age of specimens

for the round stem $(r=0,887, p<0.05)$ than it was for the rectangular cross-sectional stem $(r=0.563, p>0.05)$.

Figure 4 shows a comparison of the stem size determined virtually from the digitalised X-rays and the stem size that actually caused the humerus to fracture under the experimental conditions. Whilst the fracture occurred at the size of rectangular cross-sectional stem determined preoperatively on the X-ray or with an even larger broach (safe zone), fractures caused by the round stem in two humeri occurred at a size less than that determined pre-operatively (danger zone).

The analysis of the type of fracture in the two test series showed that fractures were always longitudinal for both prosthetic designs. There were no cases at all of complex factures such as multiple fragment fractures of the humeral shaft. 
Fig. 4 Difference between stem size determined virtually on the $\mathrm{X}$-ray and the stem size that caused the fracture. Negative value represents fracture with a smaller size than planned (danger zone), and positive value represents fracture with a bigger size than planned (safe zone)

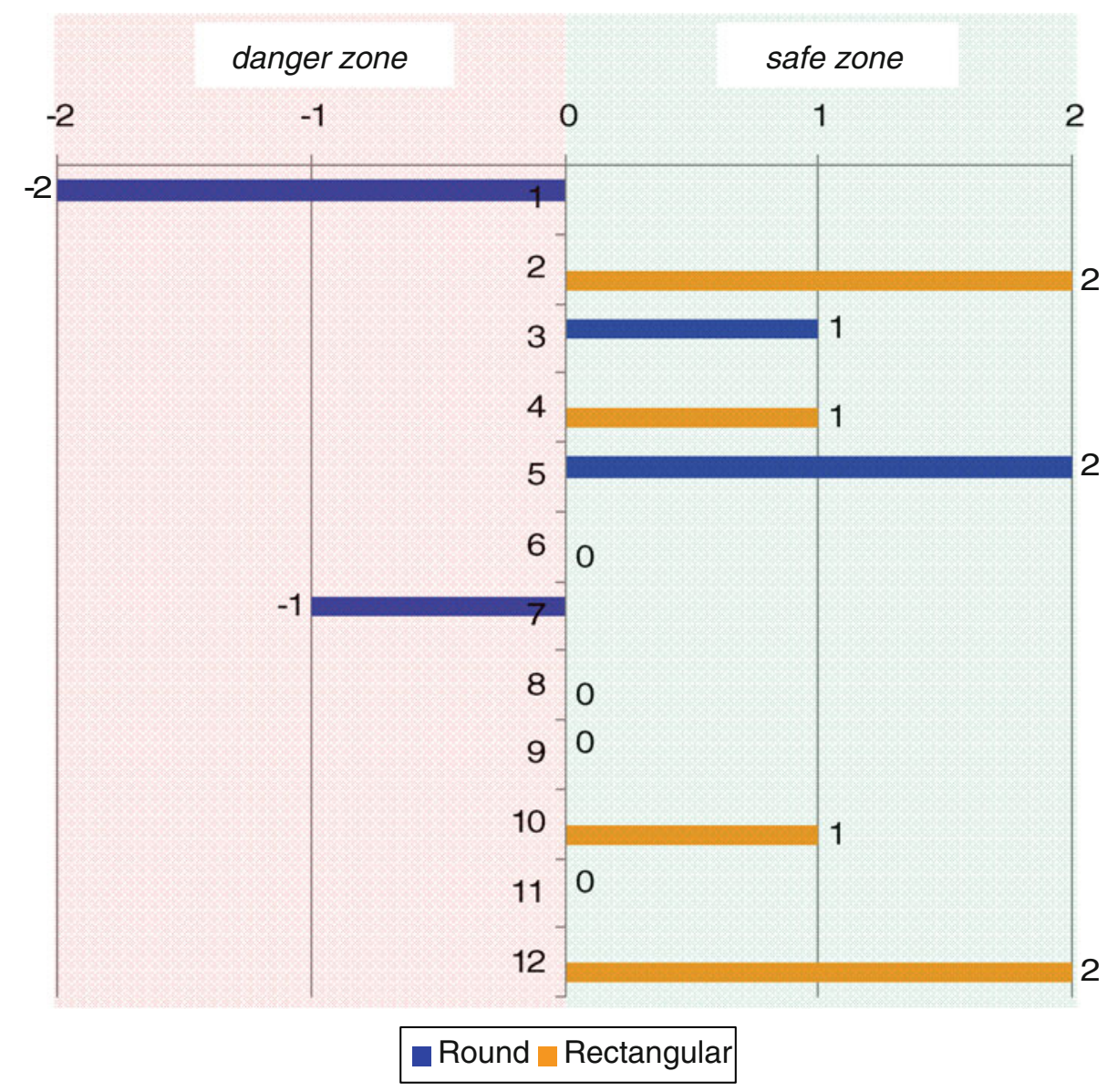

without causing the bone to fracture. Rotation of the rectangular cross-sectional stem at first induced elastic deformation of the humerus in the diaphysis and then a longitudinal diaphyseal fracture, confirming that the rectangular stem was fixed mainly in the diaphysis.

Once the humerus had fractured, metaphyseal compression was analogous to that seen with the round stem, giving a characteristic shape to the torsional moment trace. Whilst the increase in torque was almost linear for the round stem, the rectangular stem showed a steep increase within the first few degrees (Fig. 6). The humeral shaft then fractured, which was identified by a short drop in force, followed by a linear increase in torque that was almost parallel to the curve obtained with the round stem (Fig. 7).

The correlation between the maximum torsional moment and the trabecular density measured (BMD) was significant $(r=0.62, p<0.05)$ : the higher the BMD, the higher was the maximum torsional moment.

\section{Discussion}

Uncemented prosthesis stems are required to have very good primary stability. This allows both early postoperative

Fig. 5 Mean torque [Nm] for selected angles 

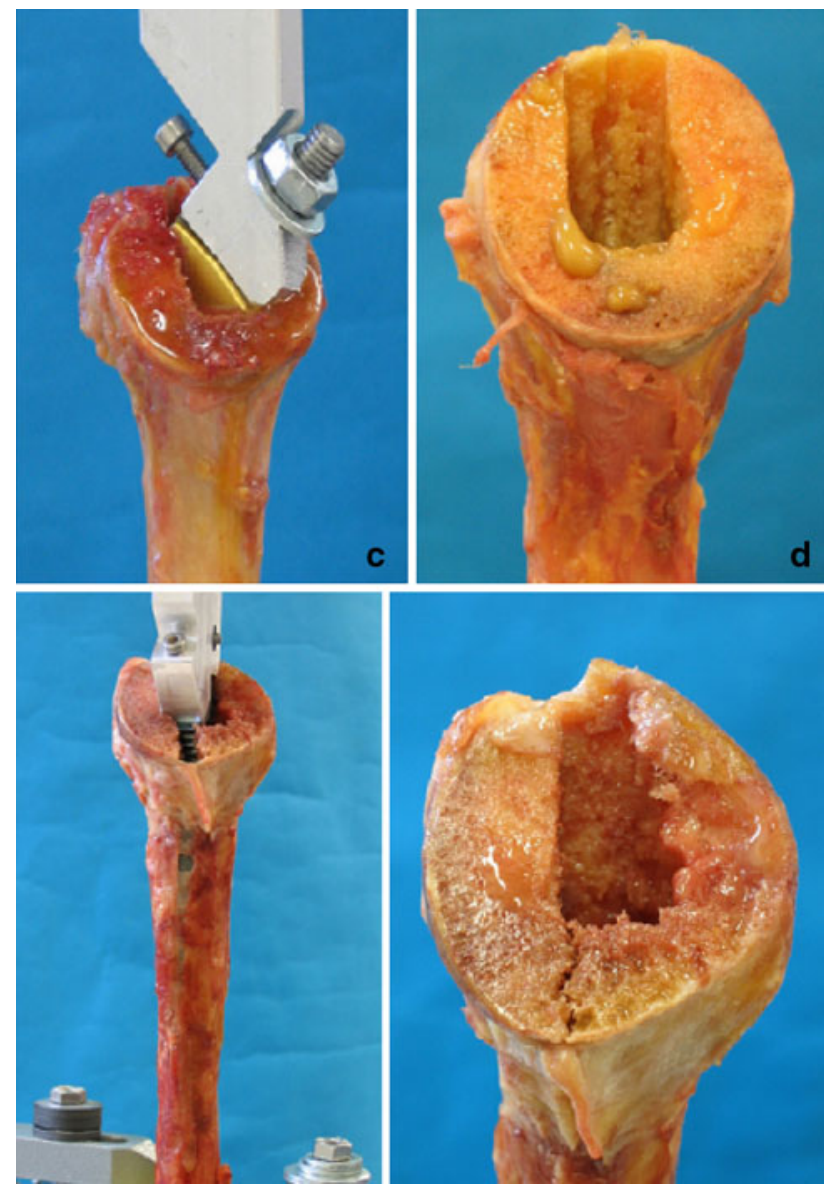

Fig. 6 Comparison of the different failure modes. Top row with typical metaphyseal compression of the round stem without diaphyseal fracture. Bottom row diaphyseal fracture of the rectangular stem

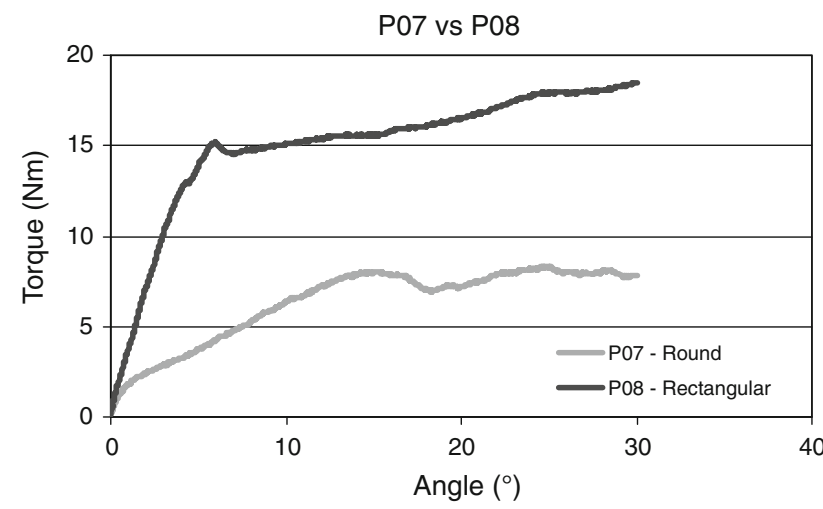

Fig. 7 Example of a force-angle diagram with a rectangular shaft in specimen 07 and a round shaft in specimen 08

functional treatment and promotes bone growth into the surface of the prosthesis. However, cementless fixation with good primary stability carries an inherent risk of fracture during implantation.

In the study presented here, we showed that primary rotational stability depends not only on biological parame- ters, but also on the design of the prosthesis. Older bones and lower BMDs result in less stable implants and also increase the risk of humeral fracture.

Looking at the results with respect to the different prostheses, the rectangular cross-sectional design has significantly greater rotational stability than the round stem. This can be attributed to the different fixations; whilst the rectangular stem is anchored predominantly in the diaphyseal area, the round shaft is anchored predominantly in the metaphysis. Metaphyseal fixation is a problem particularly in elderly patients, as age-related osteoporosis above all affects this region of the bone. Although the shoulder is not a weight-bearing joint primary torsional stability is important. Through the anatomic reconstruction of the normal centre of rotation of the humeral head with its posteromedial offset in relation to the humerus shaft axis, a torsional moment acts upon the shaft prosthesis during loaded glenohumeral motion. The shaft must be able to resist this torsional moment because only complete shaft stability allows a bony ingrowth and therefore a secondary long-term stability of an uncemented prosthesis. This design might therefore reduce the risk of long-term loosening indicated by radiolucent lines for a couple of uncemented prostheses with a round humeral shaft $[7,10,12]$.

On the basis of our data, the advantage of good primary stability does not carry an inherent increased risk of fracture. We found no significant difference between round and rectangular stems in inducing humeral shaft fractures. With increasing specimen age, less force was required to fracture the bone with both prosthetic designs, although this relation was more marked in the case of the round stems. We also attribute this result to differences in the reduction of BMD, as the metaphysis is more affected by osteoporosis than the diaphysis. In the clinical practice, therefore, a cemented implantation has to be considered for patients with a higher age and a low bone mineral density.

With the rectangular design, fractures did not occur at a prosthesis size less than that determined preoperatively using templates on the $\mathrm{X}$-rays. This is an important factor for routine clinical practice. It means that proper preoperative planning of the rectangular stem on X-rays can reduce the risk of fracture, as long as the radiological planned stem size is not exceeded at operation. With the round stem design used, two fractures occurred at a size less than the stem planned. Since the planning was made in a similar way, we believe that this might be a specific problem in planning the round stem design used in this setup (Fig. 8).

If, despite everything, the humerus does fracture on implantation, our data show that there is no need to fear a complex fracture pattern. In the two test series, both designs gave rise solely to longitudinal fissures. In contrast to multiple fragment fractures, longitudinal fractures are relatively simple to treat by means of cerclage, for example $[1,14]$. 
Fig. 8 Preimplantation planning with the specific manufacturer's templates on the same bone. The rectangular shaft shows a clear fixation zone in the proximal diaphysis of the round stem. The contact areas in the round stem may vary by adjusting the metaphyseal angle of the prosthesis to the head angle of the bone
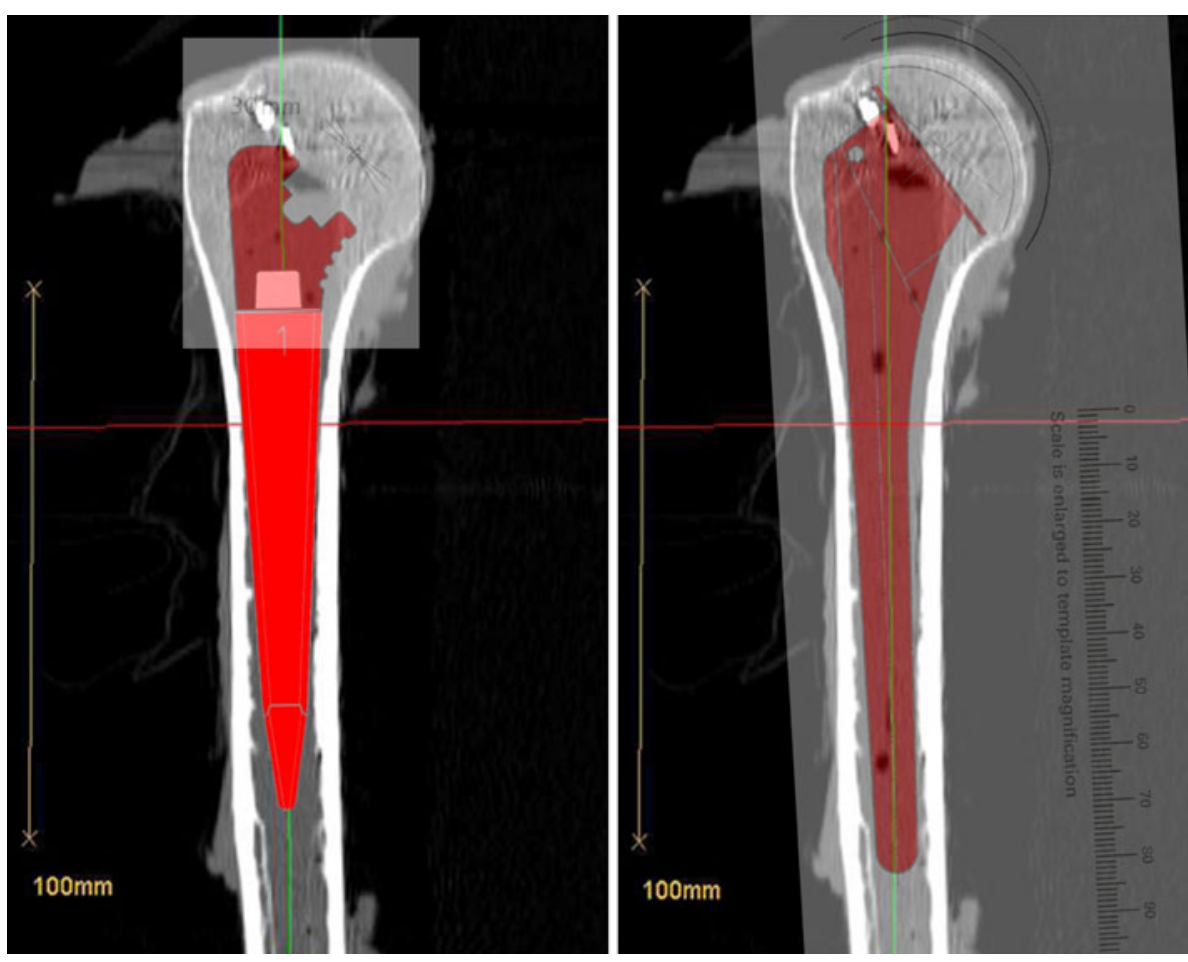

The limitations of our study are the limited number of samples in the test series, which reduces statistical power and the quasi-static loading for fracture creation that had to be chosen for reasons of reproducibility. Therefore, the results can be extrapolated only to a limited extent to the real-life situation of dynamic prosthesis implantation in the operating theatre. In summary, a rectangular cross section of the stem can improve primary rotational stability of uncemented humeral shaft prostheses without increasing the risk of fracture.

Acknowledgments This work was funded by a grant of the Swiss Society for Orthopaedic Surgery (SGO). The grant was used for the biomechanical laboratories involved in the data collection.

Conflict of interest The authors declare that they have no conflict of interest.

Open Access This article is distributed under the terms of the Creative Commons Attribution Noncommercial License which permits any noncommercial use, distribution, and reproduction in any medium, provided the original author(s) and source are credited.

\section{References}

1. Campbell JT, Moore RS, Iannotti JP, Norris TR, Williams GR (1998) Periprosthetic humeral fractures: mechanisms of fracture and treatment options. J Shoulder Elbow Surg 7(4):406-413

2. Godeneche A, Boileau P, Favard L, Le Huec JC, Levigne C, NoveJosserand L, Walch G, Edwards TB (2002) Prosthetic replacement in the treatment of osteoarthritis of the shoulder: early results of 268 cases. J Shoulder Elbow Surg 11(1):11-18
3. Groh GI, Heckman MM, Wirth MA, Curtis RJ, Rockwood CA Jr (2008) Treatment of fractures adjacent to humeral prostheses. J Shoulder Elbow Surg 17(1):85-89

4. Habermeyer P, Lichtenberg S, Magosch P (2004) Shoulder arthroplasty. Surgical management. Unfallchirurg 107(11):1008-1025

5. Heller MO, Kassi JP, Perka C, Duda GN (2005) Cementless stem fixation and primary stability under physiological-like loads in vitro. Biomed Tech (Berl) 50(12):394-399

6. Lohmander LS, Engesaeter LB, Herberts P, Ingvarsson T, Lucht U, Puolakka TJ (2006) Standardized incidence rates of total hip replacement for primary hip osteoarthritis in the 5 Nordic countries: similarities and differences. Acta Orthop 77(5):733-740

7. Matsen FA 3rd, Iannotti JP, Rockwood CA Jr (2003) Humeral fixation by press-fitting of a tapered metaphyseal stem: a prospective radiographic study. J Bone Joint Surg Am 85-A(2):304-308

8. McDonough EB, Crosby LA (2005) Periprosthetic fractures of the humerus. Am J Orthop 34(12):586-591

9. Nunn D, Freeman MA, Tanner KE, Bonfield W (1989) Torsional stability of the femoral component of hip arthroplasty. Response to an anteriorly applied load. J Bone Joint Surg Br 71(3):452-455

10. Sanchez-Sotelo J, Wright TW, O’Driscoll SW, Cofield RH, Rowland CM (2001) Radiographic assessment of uncemented humeral components in total shoulder arthroplasty. J Arthroplasty 16(2): 180-187

11. Simmen BR, Schwyzer HK, Flury MP, Goldhahn J (2009) In situ assembly of a modular noncemented total shoulder prosthesis for the reconstruction of complex joint pathology. Oper Orthop Traumatol 21(1):35-50

12. Sperling JW, Cofield RH, O'Driscoll SW, Torchia ME, Rowland CM (2000) Radiographic assessment of ingrowth total shoulder arthroplasty. J Shoulder Elbow Surg 9(6):507-513

13. Whiteside LA, McCarthy DS, White SE (1996) Rotational stability of noncemented total hip femoral components. Am J Orthop 25(4):276-280

14. Williams GR Jr, Iannotti JP (2002) Management of periprosthetic fractures: the shoulder. J Arthroplasty 17(4 Suppl 1):14-16 